\title{
JESÚS ESTEBAN, CÁRCAR BENITO: EL DERECHO A LA ASISTENCIA SANITARIA EN UN CONTEXTO DE INDIVIDUALISMO INSTITUCIONALIZADO. SUS CONSECUENCIAS ${ }^{1}$.
}

\section{THE RIGHT TO HEALTH CARE IN A CONTEXT OF INSTITUTIONALIZED INDIVIDUALISM. ITS CONSEQUENCES.}

RESUMEN: En el derecho a la asistencia sanitaria el respeto a la "autonomía del paciente" es uno de los principios fundamentales en los que se basa su ejercicio. Este principio tiene en cuenta la libertad y responsabilidad del paciente, que decide lo que es bueno para él, aunque ello no sea compartido por el profesional. La individualización institucional en el mundo actual consiste en hacer que la identidad humana deje de ser un dato para convertirse en una tarea, y en cargar sobre los actores la responsabilidad de la tarea y de la consecuencia (y efectos secundarios). En otras palabras, consiste en establecer una autonomía de iure (aunque no necesariamente de facto).

In the right to healthcare, respect for "patient autonomy" is one of the fundamental principles on which it is based.

ABSTRACT: This principle takes into account the freedom and responsibility of the patient, who decides what is good for him, even if it is not shared by the professional. The institutional individualization in the world we live in is to make human identity stop being a data to become a task, and to burden the actors with responsibility for the task and the consequence (and side effects). In other words, it consists in establishing a de jure autonomy (although not necessarily de facto). PALABRAS CLAVE: individualismo, instituciones, asistencia sanitaria

KEYWORDS: individualism, institutions, healthcare.

\section{INTRODUCCIÓN}

El derecho a la asistencia sanitaria constituye un verdadero derecho, con algunas restricciones, que tienen que ver con la extensión de la prestación reclamada, como indica Lora, si bien su amplitud no nos lleva a un concepto de salud, en un genérico aseguramiento de la felicidad individual. Por otra parte, el hecho de que la obligación de protección de la salud no pueda declinar universalmente sobre los individuos en general, puesto, que estamos "ante el despliegue de acciones que exigen una pericia y conocimiento técnico especial"2.

La enfermedad es un tipo de riesgo que aceptablemente no dejará de existir afectando a individuos determinados, al propio tiempo es un evento cuya actualización en siniestro es económicamente evaluable. Reúne así, la enfermedad las dos tipologías precisas para poder ser objeto de norma de la seguridad social. Pero también podría decirse que se alude al destinatario del correspondiente deber como es el caso de la asistencia sanitaria, es decir, a la sociedad en su conjunto.

\footnotetext{
${ }^{1}$ Doctor en Derecho. Universidad Nacional de Educación a Distancia. Este trabajo está realizado dentro del Proyecto DER 2013-41462-R financiado por el Ministerio de Economía y Competitividad.

${ }^{2}$ LORA P.; ZUÑ̃IGA FAJURI A., El derecho a la asistencia sanitaria. Un análisis desde las teorías de justicias distributivas, lustel, Biblioteca Jurídica Básica, pp. 197-198.
} 
Vivimos en una sociedad individualizada. La individualización es una compulsión, aunque paradójica, a crear y modelar no sólo nuestra propia biografía personal, sino también las redes y los lazos que la rodean y, hacerlo entre preferencias cambiantes y en las sucesivas fases de la vida mientras no vamos adaptando de manera interminable, a las condiciones del sistema sanitario. Por ello, se podría afirmar que su configuración alude en el caso de la asistencia sanitaria tanto al contenido de este derecho en sentido estricto, como a las exigencias socioeconómicas que se pretenden satisfacer como es la salud. En esta búsqueda la pregunta básica es la siguiente: ¿qué ocurre cuando las exigencias de la "sociedad individualizada" se combina o incluso se alían, con las nuevas posibilidades que ofrece la tecnología?, ¿qué forma de entender el derecho a la asistencia sanitaria puede aguardarnos sobe está base?

En el mundo actual la vinculación del legislador por el reconocimiento constitucional de los derechos sociales también se ha hecho más evidente en la medida en que, primero la doctrina y luego los tribunales, confieren a estos los principios de una estructura compleja. Reconocen derechos subjetivos, protegen instituciones, y proclaman valores que los legisladores tienen que respetar y procurar realizar. Ésta última vertiente objetiva de los derechos condiciona al legislador. El derecho a la asistencia sanitaria otorga un ámbito de libertad que abre al paciente un conjunto de derechos que obtienen su correspondiente protección, mediante la imposición de obligaciones a los profesionales y centros sanitarios, que se insertan en el desarrollo de la correcta prestación. Esta incluye no solo la apropiada prestación técnica, sino también el deber de información y respeto a las decisiones adoptadas por el paciente libre y voluntariamente

Desde la perspectiva del mundo actual, la individualización supone que los rasgos de los procesos asistenciales no solo permiten, sino que también exigen una activa contribución por parte de los individuos ${ }^{3}$. Por ello, este trabajo intenta indagar dentro de tres elementos (el sujeto titular del derecho, el sujeto obligado y el objeto del contenido), parte de una noción concreta, si antes la salud era algo que nos era dado y que sólo exigía reapariciones en caso de emergencia, ahora es algo que tiene que ser constantemente producido. La pregunta es: ¿Éste es un peligro que amenaza la realización del derecho a la asistencia sanitaria, como lo entendemos ahora, autonomía del paciente, y que da origen a una nueva moral en salud? Es decir, de derecho subjetivo entendido como un correlato de una obligación (claim-right) de "responsabilidad".

\section{EL INDIVIDUALISMO SANITARIO: REFLEXIONES PREVIAS}

a) La autonomía del paciente

La autonomía del paciente como bien jurídicamente protegido surge como una manifestación de la libertad humana y del reconocimiento de su dignidad y valor de la persona, tal y como ha sido plasmada en la Declaración Universal de los Derechos del Hombre-. En el ámbito de la salud el derecho a decidir libremente fue incorporado a la Ley 14/1986, de 25 de abril, General de Sanidad. (BOE 101/1986, de 29 de abril de 1986) otorgando un ámbito de libertad que abre al paciente un conjunto de derechos que obtienen su correspondiente protección, mediante la imposición de obligaciones a los centros sanitarios, que se insertan en el desarrollo de la correcta prestación. Esta incluye no solo la apropiada prestación técnica, sino también el deber de información y respeto a

\footnotetext{
${ }^{3}$ FOUCALT M.., La inquietud por la verdad, Escritos sobre la sexualidad y el sujeto, Siglo veintiuno editores, 2003, pp.60 ss.
} 
las decisiones adoptadas por el paciente libre y voluntariamente. En este marco la norma antes citada abre paso a una ulterior regulación en la Ley 41/2002, de 14 noviembre, básica reguladora de la autonomía del paciente y de derechos y obligaciones en materia de información y documentación clínica -, que completa las previsiones que la Ley General de Sanidad enunció como principios generales. En este sentido, refuerza y da un trato especial al derecho a la autonomía del paciente.

Se ha dicho, de igual manera, que la autonomía remite a la capacidad de división y autogobierno del sujeto. Es exhibida, por tanto, a la norma que el sujeto se da a sí mismo. Cuando mencionamos el principio de autonomía estamos aduciendo a la necesidad de reconocer que "el ser humanos debe ser libre de todo control exterior y ser respetado en sus acciones vitales básicas"4. Así, con el principio precitado puede deducirse una primera definición, "viéndola como la capacidad del individuo para configurar su vida del modo que crea conveniente atendiendo a sus planes a su escala de valores y a las circunstancias en que su vida se desarrolle". Es decir, la "capacidad de los individuos de reflexionar por sí mismos y de autodeterminarse: deliberar, juzgar, elegir y actuar en diversos modos posibles de acción"6.

La concepción de autonomía planteada muestra cómo los agentes autónomos pueden entenderse a sí mismos como "autolegisladores", esto es, "como sujetos que mediante una decisión o elección libre establecen una norma que consideran vinculante. Esta pretensión, no obstante, posee tan sólo validez subjetiva, pues explica simplemente las exigencias o pretensiones normativas del propio agente, sin que nadie más resulte vinculado por ellas"7.

En el mundo actual el individuo, abrumado por los problemas, "busca allá y produce incontables autoridades que intervienen en su vida social y psíquica, las cuáles, actuando como sus representantes cualificados, le ahorran la pregunta "quén soy y qué quiero y reducen asís su miedo a la libertad. Por ello a la paradoja de la autonomía, en suma, no ha sido caracterizada todavía con una solución satisfactoria. Algunos autores niegan que tal paradoja exista, o no discuten el asunto; y otros consideran la autonomía individual como una simple metáfora ${ }^{8}$ que se refiere a la autonomía política de las comunidades. Pero se echa en falta una explicación plausible de cómo combinar las ideas de autolegislación individual y moral vinculante

\footnotetext{
${ }^{4}$ DRANE F., "La bioética en una sociedad pluralista", en Gafo. J.(ed), Fundamentación de la Bioética y manipulación genética, Dilemas éticos de la Medicina Actual 2, Madrid, UPCO, 1988, p.101.

${ }^{5}$ MARCOS DEL CANO, A.M., La Eutanasia estudio filosófico-jurídico. Madrid, Marcial Pons-UNED, 1999, pp.108-109.

GIDDENS, A., La transformación de la intimidad. Sexualidad, amor y erotismo en las sociedades modernas. Madrid, Cátedra. 4ª edición,2004, p.168.

${ }^{7}$ SIECKMANN J.R "The Concept of Autonomy" (El concepto de autonomía), en Law and Legal Cultures in the 21st Century: Diversity and Unity,Plenary Lectures of the XXIII IVR-World Congress of Philosophy of Law and Social Philosophy, Cracow: Oficina (Kluwers), 2007, pp. 149-17 (DOXA, Cuadernos de Filosofía del Derecho, 31 (2008) ISSN: 0214-8676 pp. 465-484)

${ }^{8}$ BAUMANN, P., Die Autonomie der Person,(“ The Autonomy of the Person")Paderborn: Mentis, 2001. ; BECK, L. W., A Commentary on Kant's Critique of Practical Reason, Chicago \& London: Chicago Univ. Press, 1990.
} 


\section{b) La individualidad}

En la concepción actual, la asistencia sanitaria no es una excepción, encontramos decisiones imposibles de tomar, dentro de circunstancias que desembocan en dilemas, pero también en circunstancias de los individuos ${ }^{9}$. La sociedad actual configura la individualidad de sus miembros y a los individuos que forman la sociedad a partir de "acciones vitales" de éstos. La modernidad sustituye a la determinación del status social con una autodeterminación compulsiva y obligatoria.

En consecuencia, ante un mundo que presenta, a la vez, una mayor incertidumbre y una mayor categoría de opciones, los seres humanos se ven obligados a optar entre una dilatada gama de oportunidades. Forjar a los miembros como individuos es la señal registrada de la sociedad moderna. "La intensificación del proceso de individualización, propio de la modernidad tardía, lleva a que la identidad deje de ser un "dato" para convertirse en una tarea" 10 y en cargar sobre los actores la responsabilidad de la tarea y las consecuencias (y efectos secundarios de una tarea). "Los hombres y mujeres de hoy en día ya no tienen a nadie a quien culpar por sus éxitos y fracasos y las condiciones de la vida colectiva deben renegociarse continuamente según los diversos casos"11 .En otras palabras, consiste en establecer una autonomía de iure (aunque no necesariamente de facto). De acuerdo con las tesis de Beck, en el contexto de la individualización, la propia existencia es vivida como una biografía reflexiva y electiva, que se expresa en el mandato "hágalo usted mismo" La promesa de la modernidad "que nació de la reivindicación del poder del sujeto" se cumple con creces en las sociedades contemporánea y la necesidad de "llevar una vida propia", que antes era patrimonio de unos cuantos, se muda en una exigencia para un creciente número de seres humanos que tienen que desarrollar su individualidad en un mundo" desbocado". Los seres humanos de hoy en día, se perciben como si fueran desincrustados de la sociedad. Están pretendiendo hallar soluciones "biográficas" a contradicciones sistémicas sin alcanzar a concebir que el individualismo propio de la "sociedad de riesgo" es resultado del desequilibrio institucionalizado en las nuevas condiciones de globalización ${ }^{12}$.

En este contexto, las crisis cesan de ser percibidas en su dimensión social, las formas de vida se "destradicionalizan" y las personas luchan de modo compulsiv0 por vivir su propia vida en un mundo que cada vez se les escapa más y donde las recetas y los estereotipos sobre los roles han dejado de funcionar $^{13}$. El individualismo moderno emerge en el contexto de cambio colectivo y de una socialización confusa, contingente y con altos niveles de diferenciación. La imagen de un yo "humano y autárquico", que presupone que los individuos dominan por sí mismos la totalidad de sus vidas, se contrapone constantemente a la experiencia cotidiana y a la mirada sociológica que no puede concebir

9 BECK U.\& BECK-GERNSHEIM E, La individualización. El individualismo institucionalizado y sus consecuencias sociales y políticas, Barcelona, Paidós, 2003, p. 41-42

${ }^{10}$ Ibídem, pp.43ss.

${ }^{11}$ BAUMAN ZYGMUNT, "Individualmente, pero juntos", en Ulrich Beck y Elizabeth Beck-Gernsheim, La individualización. El individualismo institucionalizado y sus consecuencias sociales y políticas, Barcelona, Paidós, 2003, pp.. 20-22

12 ZABLUDOVSKY, G. "En torno a la democracia, la igualdad y la libertad. Un diálogo imaginario entre Lorenzo de Zavala y Alexis de Tocqueville", en Sociología y política. El debate clásico y contemporáneo, México, UNAM/Porrúa, 1995

${ }^{13}$ BECK U.\& BECK-GERNSHEIM E, La individualización........cit..p.38-68 
al individuo sino es en sus relaciones con el mundo del trabajo, la familia y las redes e instituciones globales.

¿Hasta qué punto esta forma de individualismo se opone a los procesos de integración social en la asistencia sanitaria y hasta dónde los hace posibles? Bauman asevera que el otro lado de la individualización semeja ser la desintegración de la ciudadanía"14. Desde una perspectiva más optimista, Lipovetsky contempla que la posmoralidad nunca debe "leerse" como sinónimo de inmoralidad. En la sociedad actual, el relativismo no puede hacerse equivalente a un nihilismo. Así, "la desaparición de la moral incondicional no se ha traducido en una proliferación de conductas egoístas en el conjunto del cuerpo social"15.

En el desarrollo de la asistencia sanitaria, hay dos cuestiones a tener en cuenta. Por una parte, la tecnología es vista como un destino: las aplicaciones biotecnológicas mismas dictan si y de qué manera se van a aplicar. Por otro lado, está la posición del reduccionismo social, según el cual, son los usuarios de la asistencia sanitaria quiénes deciden si y de qué manera se aplicará la tecnología. La pregunta sería: ¿En qué medida esta individualización produce una merma en la relación profesional-paciente? A mi juicio, siguiendo a Rorty, los ámbitos de la cultura — tanto la ética como la física - en un sentido de "estar en contacto con" que no significa "representación razonablemente exacta", sino simplemente "causado y causante" 16 .

\section{EL PROCESO ASISTENCIAL}

Como señala Beck hay un proceso en espiral en relación con la tecnología, y, en concreto, con la ingeniería genética en cuanto que aplica a los seres humanos. De ahí que no sean infrecuentes en el ámbito sanitario las situaciones que son problemáticas desde el punto de vista ético y jurídico, e incluso situaciones en las que entran en conflicto diferentes derechos fundamentales de las personas afectadas. La pregunta básica es la siguiente: ¿qué ocurre cuando las exigencias de la sociedad individualizada se combinan, o incluso se alían, con las nuevas posibilidades que ofrece la tecnología? ¿Qué forma de futuro puede aguardarnos sobre esta base? $Y$ de ahí también que haya un espacio muy importante para las regulaciones deontológicas y para el tratamiento legal específico de determinadas actuaciones (hemodonación y transplantes de órganos, experimentación clínica, reproducción asistida, esterilización, etc.). Pero además, las características de la actividad sanitaria asistencial -en la que las situaciones difíciles y doloras para los enfermos y sus familias no son en general excepcionales- disponen también un rasgo diferencial respecto a otros servicios y prestaciones públicas: hacen que la materia no pueda enfocarse exclusivamente con meras pautas de gestión burocrática, ni tampoco de simple eficiencia gerencial, sino que se requiere un, una especial atención desde el punto de vista de "la individualización, la dignidad y la humanidad en el trato a los pacientes y sus familiares" 17 .

\footnotetext{
${ }^{14}$ BAUMAN ZYGMUNT, "Individualmente, pero...... op. cit., pp. 24-25.

15 CHARLES S., "El individualismo paradójico. Introducción al pensamiento de Gilles Lipovetsky", en Gilles Lipovetsky y Sébastien Charles, Los tiempos hipermodernos, op. cit., p.

${ }_{17}^{16}$ RORTY R. "Objetividad, relativismo y verdad", Paidos, 1996,pp 39-57

17 Ley $1 / 2015$, de 9 de febrero, de derechos y garantías de la dignidad de la persona ante el proceso final de su vida. «BOE» $\mathrm{n}^{\circ} 54$, de 4 de marzo de 2015
} 
Junto a ello, creo que debe incidirse también la gran preeminencia que en la prestación de la asistencia sanitaria tienen los elementos personales -quién facilita la asistencia sanitaria- y temporales -cuándo se presta-, así como las condiciones del lugar o contexto físico en que se lleva a cabo. Por lo que se refiere al primer aspecto, importa subrayar el ambiente de libertad y confianza que ha presidido tradicionalmente la relación médico-paciente y el carácter no fungible que se ha venido atribuyendo a la prestación de servicios médicos - logrados intuitu personae, esto es, en atención a las cualidades profesionales del médico y a la confianza otorgada al mismo su carácter institucionalizado.

\section{a) El problema de las prestaciones}

Por último, constituye también un aspecto destacable a mi modo de ver las dificultades que para la fijación del contenido de las prestaciones sanitarias derivan de la multidimensionalidad de lo sanitario y del carácter difuso que separan la asistencia sanitaria respecto a otras problemáticas próximas o afines. Al respecto cabe aludir por ejemplo a las actuaciones que se llevan a cabo en ámbitos sanitarios, pero cuya conjunción con la salud de las personas afectadas puede ser tan sólo mediata o indirecta o incluso puede llegar a desaparecer: así, las intervenciones en el espacio de la cirugía estética o de la cirugía transexual que se incluyen dentro de lo que se considera Medicina no curativa o "voluntaria". En tales casos se hace necesario especificar, dentro de lo médicamente posible, aquello que se asume como prestación pública del sistema sanitario y se reconoce como tal en la normativa correspondiente.

La Ley 16/2003, de 28 de mayo, de cohesión y calidad del Sistema Nacional de Salud (LCC) en su Capítulo I articula a través del catálogo de prestaciones del SNS la garantía de las condiciones básicas y comunes para una atención integral, continuada y en el nivel adecuado de atención, definiendo las prestaciones de atención sanitaria del SNS los servicios o conjunto de servicios preventivos, diagnósticos, terapéuticos,

Por tanto, el primer límite a la autonomía del paciente es el de las propias prestaciones indicadas. De forma aún más explícita, el Real Decreto Real Decreto 1030/2006, de 15 de septiembre, por el que se establece la cartera de servicios comunes del Sistema Nacional de Salud y el procedimiento para su actualización, indica en su artículo 2.4 lo siguiente: "Los usuarios del Sistema Nacional de Salud tendrán acceso a la cartera de servicios comunes reconocida en este real decreto, siempre que exista una indicación clínica y sanitaria para ello". Aquello que está indicado, y que se encuentre dentro de la cartera de servicios del Sistema Nacional de Salud. $Y$ todo ello en condiciones de igualdad efectiva. No se contemplan, en el ordenamiento jurídico, otras limitaciones a la autonomía de la voluntad por razones de justicia que las previstas en las normas que delimitan la cartera de servicios del Sistema Nacional de Salud ${ }^{18}$. El reconocimiento de una cartera de servicios aparece como un elemento de considerable convicción que delimita la capacidad del propio paciente. $\mathrm{O}$ en un sentido, en cierto modo inverso al mencionado, cabe considerar determinados cuidados corporales que tienen una indudable relación con la salud -como los tratamientos en balnearios y las curas de reposo- pero que quedan al margen del sistema público de asistencia sanitaria.

Para incorporar nuevas técnicas, tecnologías o procedimientos a la Cartera de servicios comunes o excluir los ya existentes, será necesaria su evaluación. Para llevar a

\footnotetext{
${ }^{18}$ CÁRCAR BENITO, J., "La cartera de servicios y su necesidad dentro de la configuración del derecho a la salud: configuración y categorización”, Derecho y Salud, Vol. 2, ㄲo 2 - 2014
} 
cabo la actualización se deberá utilizar el procedimiento de evaluación más adecuado en cada caso que permita conocer el coste, la eficacia, la eficiencia, la efectividad, la seguridad y la utilidad sanitaria de una técnica, tecnología o procedimiento, como informes de evaluación, criterio de expertos, registros evaluativos, usos tutelado ${ }^{19}$.

En otro orden de cosas es preciso tener en cuenta que los Servicios de Salud entran en contacto ineludiblemente con situaciones de necesidad de individualidad en las que las cuestiones de salud aparecen reducidamente vinculadas a otros aspectos o perspectivas. La hospitalización conlleva, como es obvio, una relación especialmente intensa con los Servicios de Salud, lo que otorga una gran importancia a todas las cuestiones vinculadas al acondicionamiento material del enfermo. La LCC manifiesta que promoverá, lo que supone una aspiración, la incorporación progresiva de habitaciones de uso individual en los centros hospitalarios del Sistema Sanitario Público (art. 28.1 LCC). A estos efectos, se procurará garantizar la disponibilidad de estas habitaciones individuales para aquellos pacientes en que así sea aconsejable por sus especiales circunstancias Es decir, de utilización de habitación de uso individual a petición de los pacientes, sus familias o personas vinculadas de hecho a los mismos. Es el caso de los enfermos en estado terminal y en estado agónico o preagónico, las pacientes de la especialidad de obstetricia y el de los menores. Esto cobra su importancia en el proceso de la muerte.

\section{b) La terapia génica y la individualidad}

La terapia génica es el conjunto de técnicas que utilizan la transferencia de material genético (o cualquier otro método que permita editar o modificar la información genética del paciente) para prevenir o curar enfermedades genéticas. Sin duda es la mejor alternativa de todas las posibles, pero probablemente también la más compleja. En los últimos años se ha producido un extraordinario desarrollo lo que ha permitido, entre otros avances, identificar genes candidatos para enfermedades complejas con una alta prevalencia en la población, relacionar las interacciones de estos genes entre sí y con modificadores ambientales, desarrollar pruebas diagnósticas para identificar a los individuos en riesgo, potenciar una medicina preventiva personalizada a través de exámenes médicos que orientan la modificación de comportamientos o hábitos a la medida de la persona o utilizar terapias farmacológicas adecuadas al genotipo de cada individuo. Hay un gran número de situaciones diferentes, pero no del todo mutuamente excluyentes. Si las posibilidades proféticas y prospectivas del análisis del genoma siguen aumentando, puede que se produzca una paulatina "individualización" de los riesgos asociados a la salud. Esta tendencia ya se puede apreciar independientemente de los riesgos genéticos conduce a un llamamiento a los más variados ámbitos, a una mayor responsabilidad en materia de atención sanitaria ${ }^{20}$.

La maleabilidad de la vida, por tanto, ha ganado en alcance e importancia. Una combinación de medicina, bilogía y genética ha formado una nueva manera de intervenir en la materia misma de la existencia humana, hasta el punto de que vuelven a plantearse las preguntas de qué es, debería ser y puede ser el hombre. En la formación del consenso necesario juega un papel protagónico esencial el derecho como elemento ordenador de la sociedad y -en última instancia- como normativa en cuya elaboración no sólo juega el arbitrio del legislador. Si el derecho es norma -según lo entiende Kaufmann- entonces no se puede conformar con la legalidad, pues la norma exige moralidad. En esta exigencia de

\footnotetext{
${ }^{19}$ La Ley 16/2003, de 28 de mayo

${ }^{20}$ BECK U.\& BECK-GERNSHEIM E, La individ.... op.cit.p262-263
} 
moralidad se da la conexión entre bioética y derecho ${ }^{21}$.Con el auge y la difusión de las nuevas tecnologías, la plasticidad de la vida ha ganado en alcance e importancia. La nueva biotecnología admite que el hombre se puede fabricar a sí mismo, damos a estas palabras un nuevo sentido ${ }^{22}$.

\section{c) La salud pública como valor guía en una sociedad individualizada}

En la sociedad actual, los procesos de individualización han dado a la salud y a la responsabilidad el carácter de valores guía, que influyen enormemente en la futura y preparan el terreno para la aceptación, por ejemplo, del genoma humanos. Es el caso de la atención a las personas con enfermedades crónicas o degenerativas y a las personas de edad avanzada con limitaciones funcionales importantes. Otra atención que requiere una asistencia preventiva, los ruidos, el medio ambiente, la detección precoz, la alimentación, el stress y su prevención, el derecho laboral en su faceta de prevención de accidentes y enfermedades laborales, los primeros auxilios, el deporte. Esto es el conjunto de servicios que el SNS ofrece a los ciudadanos e incluye actividades preventivas, diagnósticas, terapéuticas, rehabilitadoras y de promoción y mantenimiento de la salud.

Para ver mejor esta tendencia, la Ley 33/2011, de 4 de octubre, General de Salud Pública (BOE no 2405 de octubre de 2011) viene a optar por un modelo basado en la voluntariedad ${ }^{23} \mathrm{y}$, por tanto, en el principio de autonomía, en el que las actuaciones de salud pública de naturaleza coercitiva habrán de ser excepcionales. Así se proclama en el artículo 5.2 cuando se dispone que "sin perjuicio del deber de colaboración, la participación en las actuaciones de salud pública será voluntaria. El cuidado preventivo, es según Daele, es un elemento de autogestión que se espera de las personas modernas individualizadas. Cuando de modo metódico se convierte en práctica establecida- desde el a planificación de la educación [...] hasta la provisión de una vejez "feliz"-, entonces el cuidado sanitario preventivo debe convertirse en una prioridad ${ }^{24}$.

Es verdad que hay razones excepcionales, por ejemplo, el internamiento no voluntario por razón de trastorno psíquico, pero no por ello ajenos a la salud pública, siendo un ejemplo paradigmático de ello el campo de la vacunación ${ }^{25}$, al que sí se refiere mínimamente la Ley 33/2011, y que actualmente constituye uno de los principales instrumentos con los que cuenta la salud pública para la prevención de enfermedades que hasta hace pocos años eran capaces de destruir comunidades enteras ${ }^{26}$.

\footnotetext{
${ }^{21}$ KAUFMANN A. Filosofía del Derecho. Bogotá: Editorial Universidad Externado de Colombia; $1995: 395$.

22 RIFKIN J., El siglo de la biotecnología, Crítica Marcombo, Tecnología y Humanismo,1999, pp.166-167

23 BELTRÁN AGUIRRE, J.L., "Bioética y Derecho biomédico: principios informantes. su reflejo en la normativa y en la práctica asistencial. Enfrentamientos, prevalencias y transgresiones", Derecho y Salud, vol. 24, núm. 1, año 2014, p. 26.

24 VAN DEL DAELE W.,Mensch nach Maß. Ethische Probleme der Genmanipulation und Gentherapie (= Beck'sche schwarze Reihe. Bd. 299). Beck, München 1985, citado en D'Agostino, Elementos para una filosofía de la familia Universidad de Navarra, 2002.

25 DE MONTALVO JÄÄSKELÄINEN, F. "Rechazo a las políticas públicas de vacunación. Análisis constitucional del conflicto desde los sistemas español y norteamericano", Derecho privado y Constitución, n.ำ 26, enero-diciembre, 2012, pp.. 203 a 237. DE MONTALVO. "El paradigma de la autonomía en salud pública ¿una contradicción o un fracaso anticipado?: el caso concreto de la política de vacunación”, Derecho y Salud, vol. 24, núm. Extraord., 2104, pp.. 27-40.

26 PARMET, W.E., "Public Health and Constitutional Law: Recognizing the relationship", Journal Of Health Care Law \& Policy, vol. 10, 2007, p. 22.
} 
El modelo actual, empero, se fundamenta más en una base educativa que coercitiva.. Así, en el Preámbulo de la precitada Ley 33/2011 dispone a este respecto que Como tal, la salud pública habría de funcionar en el difícil equilibrio entre intereses individuales e intereses colectivos como un límite a aquellos. Gostin nos ofrece una interesante definición del Derecho a la salud pública que permite apreciar dicha "dimensión colectiva"27. Sin embargo, en este campo por la individualización hay un debe que no implica compulsión directa, pero aun significa una elección puramente libre. Podríamos hablar, por paradójico que pueda parecer de una compulsión voluntaria o, como hace Daele, de una compulsión preventiva. Las medidas preventivas obtienen fácilmente estatus de legitimidad y racionalidad, y no permiten prácticamente el planteamiento de ninguna contestación. Por ello, las opciones para evitar los riesgos de salud constituyen a la vez recursos de autoplanificación y reivindicaciones de servicios públicos dirigidos al Estado. "Parece, que las demandas de servicios sociales de la comunidad en el caso de enfermedad corren parejos con la obligación de estar sanos. Obviamente, esta idea puede transmitirse a personas en perfecto estado de salud que, de manera responsable, se aprovecha de facilidades y servicios preventivos"28. Sin embargo, es en el campo genético, como he señalado, difiere de los diagnósticos tradicionales en su dimensión predictiva.

\section{d) El proceso de la muerte y la individualización}

En el juicio clínico de indicación, en aspectos como la limitación del esfuerzo terapéutico, pueden pesar, de manera decisiva, los valores del paciente, aunque la ley no lo tenga en cuenta para su determinación. De hecho, los protocolos clínicos de los centros sanitarios para la instauración de la limitación del esfuerzo terapéutico prevén un proceso completo de información y consenso con el paciente y sus allegados. Los valores del paciente, sus expectativas y posicionamientos vitales, en la práctica, son tenidos en cuenta en la determinación del juicio de indicación en esta materia. De hecho, y salvo casos extremos, las medidas de limitación del esfuerzo terapéuticas no son instauradas en contra de la decisión de un paciente, aunque puedan existir consideraciones clínicas que las desaconsejen, en un determinado momento. Conforme a la ley, no obstante, la indicación es un juicio de carácter técnico clínico. Así se indica, también, en el artículo 18 de la ley 2/2010, de 8 de abril, de Derechos y Garantías de la Dignidad de la Persona en el Proceso de la Muerte. (BOJA no 88 de 07 de mayo de 2010 y BOE no 127 de 25 de mayo de 2010): "En el caso de que este juicio profesional concluya en la indicación de una intervención sanitaria, someterá entonces la misma al consentimiento libre y voluntario de la persona, que podrá aceptar la intervención propuesta, elegir libremente entre las opciones clínicas disponibles, o rechazarla, en los términos previstos en la presente Ley y en la Ley 41/2002, de 14 de noviembre.

En suma, y desde un punto de vista jurídico, es difícil de señalar la obligación de abstenerse de imponer por parte de los profesionales criterios de actuación basados en sus propias creencias y convicciones personales, morales, religiosas o filosóficas. El miedo a morir se ha instalado en los nuevos escenarios de la seguridad y los seguros, que se supone que protegen a la existencia terrenal contra las huellas de su pasado. Así en

\footnotetext{
${ }^{27}$ GOSTIN, L.O.: "A theory and definition of Public Health Law", Journal of Health Care Law \& Policy, Vol. 10, nํ. 1, 2007.

${ }^{28}$ VAN DEL DAELE W. op.cit.208.
} 
palabras de Beck lo que ocurre al final no es tanto el que muramos como el que la medicina haya dejado de funcionar.

Esto deviene que lo que nosotros llamamos una "vida propia" no es, por tanto, ni la expresión de un "individualismo" y "egoísmo desbordante"-en palabras de Beck- "que han alcanzado proporciones epidémicas ni tampoco en la que los individuos floten libres en su autodeterminación, sino, más bien, una "vida de perfecta conformidad", vinculante para cada vez más grupos dentro del contexto de un "anhelado Estado de bienestar"29. En suma, y tal como se indica, en relación a las decisiones relacionadas con la atención sanitaria prestada en el proceso de muerte, la reacción predomínate en el momento actual es olvidar, reprimir y enterrar a la muerte, mantenerla encerrada en "las mazmorras más profundas", en las estancias más recónditas del yo. ¿No supone esto, en realidad, una llamada a la imposibilidad de acuerdo entre las partes en la adopción de las decisiones referidas a la asistencia sanitaria prestada en el proceso de muerte? El problema es que la individualización demanda "en esta vida propia" una muerte repentina sin el morir, una muerte sin ningún pensamiento en la muerte"30. Las distintas opciones en el proceso de la muerte también "generan estados de insatisfacción y vacío, dolor, desdicha, descontento y malestar"31. Estas frustraciones son resultado de sociedades con una competencia regulada y en donde se plantean objetivos que son inalcanzables para muchos el proceso de la muerte.

\section{CONCLUSIÓN: EL INDIVIDUALISMO INSTITUCIONALIZADO EN LA ASISTENCIA SANITARIA.}

El consentimiento informado, por el propio paciente o por representación, las voluntades vitales anticipadas, la información clínica, la historia clínica son instituciones que garantizan o sustancian algunos de los caracteres de la autonomía del paciente. Así, por el consentimiento informado, el paciente deberá consentir con autenticidad -esto es, con capacidad, información y sin presiones-, sobre todas las cuestiones que afectan a su salud. No obstante, la autonomía del paciente es diferente a todas esas manifestaciones de la misma. Así Diego Gracia indica que "no nos equivoquemos, el consentimiento informado no es más que una consecuencia de algo mucho más profundo, la aceptación de que el paciente es autónomo para decidir qué es y qué no es una necesidad sanitaria. Tenemos que aceptar el principio de que el usuario es quien define hoy, y sobre todo quien va a decidir en el futuro lo que es una necesidad de salud y, por tanto, lo que es salud y enfermedad." 2 . Tras esta afirmación, cabe decir, que, en el mundo actual, la voluntad de la "vida propia", depende así, por completo de las instituciones. En lugar de tradiciones vinculantes, las directrices e instituciones aparecen en escena para organizar nuestra propia vida.

La distinción cualitativamente de las historias vitales tradicionales y las modernas no es tanta como muchos suponen, En realidad es en el bosque "burocrático" e "institucional" de la asistencia sanitaria moderna donde la vida atosiga por ramas de directrices y regulaciones. La diferencia fundamental estriba en que las pautas modernas obligan de hecho a la autodeterminación y automatizaciones de las biografías individuales. La

\footnotetext{
${ }^{29}$ BECK U..\& BECK-GERNSHEIM E, La individ.... op..cit.. p264 ss.

30 lbídem, p.270

${ }^{31}$ Elías N.., La sociedad de los individuos, Barcelona, Península, 1990, pp. 151-153.

32 GRACIA, DIEGO. "Los fines de la medicina en el umbral del siglo XXI", Debática. Vol. 1, nำ2, 2012.
} 
segunda es que las normas jurídicas que avalan la autonomía del paciente mediante la garantía de instituciones instrumentales -consentimiento informado, deber de información, documentación clínica, y otras -, no se pronuncian sobre los límites del principio que les da causa. Así, encontraremos en la norma jurídica los límites a los instrumentos, pero los límites de la autonomía del paciente, de por sí, deberán ser inferidos leyendo entre líneas. Está asumido que el paciente puede negarse al tratamiento, aun cuando esto sea perjudicial para su salud y comprometa su vida. Este límite "negativo" del ámbito de la autonomía de la voluntad se garantiza mediante la institución del consentimiento informado, tal y como se contempla en la ley 41/2002, en su artículo 8 . El médico desde el paternalismo sabe lo que su paciente necesita, aunque no cuente con él para decidir, y el paciente autónomo, que decide de forma auténtica sobre su salud, son los dos extremos de esa línea que, actualmente, articula como hilo argumental principal el devenir histórico de la Bioética.

La reflexión sobre los conceptos y su revisión en un proceso de actualización permanente, permite así "problematizar el ámbito sanitario sin "reificar" las categorías y organizar la reflexión, a medio camino entre las leyes sanitarias y la realidad empírica concreta" ${ }^{\prime 3}$, y como dijo Kant en sus tres cuestiones: ¿qué puedo conocer? ¿qué puedo hacer? ¿qué puedo esperar? En otros términos, desde un punto de vista de un paciente, ¿a qué tengo derecho? ¿qué puedo pedir? ¿qué puedo hacer? Y, en consecuencia, ¿qué deberes tienen los demás, profesionales o ciudadanos, en relación con mis decisiones? El problema Kantiano es que no nos podemos presentar ante un problema dado que estamos determinados en una dirección, por que hacemos un juicio que no puede ser verificado. Pues bien, al hacernos responsable nos libramos de las condiciones anteriores existentes, porque no podemos atribuirle el concepto de "determinantes"34.

El artículo 2.3 de la ley 41/2002 señala, específicamente, uno de los límites: "EI paciente o usuario tiene derecho a decidir libremente, después de recibir la información adecuada, entre las opciones clínicas disponibles.". Para conseguir su objetivo "debe premunirse de un bagaje de normas deontológicas y éticas que colaboren a la función de control y contribuyan a crear un entramado social cohesionado"35. El primer problema es que una persona con capacidad y el derecho al autogobierno puede no tener la oportunidad de ejercer sus derechos y capacidades. La autonomía como condición hace referencia a las circunstancias que deben darse para que un individuo tenga la oportunidad de ejercer sus capacidades 0 , incluso sus derechos ${ }^{36}$. El segundo es que el avance de la tecnología, por ejemplo, la genética lleva, así la tendencia a la planificación y a la racionalización a una nueva dimensión, haciendo posible que la gente conozca sus propios factores de riesgo y los utilice para planificar sus vidas. Surge un "nuevo paternalismo", en el sentido de la vuelta a la reivindicación de las tareas tuitivas y de cuidado, que no elude las obligaciones tutelares del profesional sanitario, y que extiende estas a la

${ }^{33}$ PORTES A., "La sociología en el hemisferio. Una nueva agenda conceptual", Nueva Sociedad, núm. 178, p. 33.

${ }^{34}$ VILLACAÑAS BELANGA. J.L. Racionalidad crítica, Introducción a la filosofía de Kant, Fiolsofía y ensayos, Tecnos, 1987,pp. 194-2001.

${ }^{35}$ CASADO M. "La bioética ante las nuevas tecnologías genéticas". En: Casado M, González D, (eds.) Los retos de la genética en el Siglo XXI: genética y bioética. Barcelona: Ediciones Universitat de Barcelona; 1998 , p, 15.

${ }^{36}$ ALEMANY GARCÍA M., El paternalismo jurídico, lustel, 2006. 
autodeterminación del paciente. Habrá que encontrar una nueva definición legal que no atienda tanto a la articulación de las competencias en la determinación del juicio clínico de indicación, como a la garantía de la mejor solución, en condiciones de equidad, y vistos todos los factores determinantes para el paciente.

Empero, la salud como expectativa secular de salvación y como presión para rendir al máximo en una sociedad de mercado individualizada son dos fuerzas motrices que sustentan el auge del proyecto sanitario. El nuevo paciente, formado y emancipado, sigue la estela de los avances tecnológicos y asume la "responsabilidad de la enfermedad". La pretensión de intervenir en el juicio clínico de indicación es tornada por el papel de monitor institucionalizado de los estilos de vida de la gente "y los profesionales sanitarios el de sus policías". La auténtica autonomía persigue, a la postre, determinar las propias necesidades de salud.

\section{BIBILOGRAFÍA CITADA.}

ALEMANY GARCÍA M., El paternalismo jurídico, lustel, 200

ARTAZCOZ, L. Salud y Género, Documentación Social 127, 2002. pp: 181-205. 3.

BAUMAN ZYGMUNT, "Individualmente, pero juntos", en Ulrich Beck y Elizabeth BeckGernsheim, La individualización. El individualismo institucionalizado y sus consecuencias sociales y políticas, Barcelona, Paidós, 2003, pp. 20-22

BECK U. \& BECK-GERNSHEIM, E La individualización. El individuo institucionalizado y sus consecuencias sociales y políticas. Barcelona: Paidós, 2003.

BELTRÁN AGUIRRE, J.L., "Bioética y Derecho biomédico: principios informantes. su reflejo en la normativa y en la práctica asistencial. Enfrentamientos, prevalencias y transgresiones", Derecho y Salud, vol. 24, núm. 1, año 2014, p. 26

CASADO M. "La bioética ante las nuevas tecnologías genéticas". En: Casado M, González D, (eds.) Los retos de la genética en el Siglo XXI: genética y bioética. Barcelona: Ediciones Universitat de Barcelona; 1998, p, 15

HELENA BEJAR, La cultura del yo, Madrid, Alianza, 2002.

GIDDENS, A., La transformación de la intimidad. Sexualidad, amor y erotismo en las sociedades modernas. Madrid, Cátedra. 4aㅡ edición,2004, p.168.

GOSTIN, L.O.: "A theory and definition of Public Health Law", Journal of Health Care Law \& Policy, Vol. 10, no. 1, 2007

GRACIA, DIEGO. "Los fines de la medicina en el umbral del siglo XXI, en Como arqueros al blanco, Debática., Vol. 1, nำ2, 2012

LORA P.; ZUÑIGA FAJURI A., El derecho a la asistencia sanitaria. Un análisis desde las teorías de justicias distributivas, Iustel, Biblioteca Jurídica Básica, pp. 197-198

MARCOS DEL CANO, A.M., La Eutanasia estudio filosófico-jurídico. Madrid, Marcial PonsUNED, 1999, pp.108-109

GOSTIN, L.O.: "A theory and definition of Public Health Law", Journal of Health Care Law \& Policy, vol. 10, n‥ 1, 2007

DE MONTALVO JÄÄSKELÄINEN, F. "El paradigma de la autonomía en salud pública ¿una contradicción o un fracaso anticipado?: el caso concreto de la política de vacunación", Derecho y Salud, vol. 24, núm. Extraord. 2014., pp.. 27-40

PARMET, W.E., "Public Health and Constitutional Law: Recognizing the relationship", Journal Of Health Care Law \& Policy, vol. 10, 2007, p. 22 
PÉREZ, E., ORTEGA. E. (2014). "Cartografías del cuerpo". Biopolíticas de la ciencia y la tecnología, Madrid: Cátedra (Universidad de Valencia)(Cap. IV: Asimetrías y olvido en las tecnología de la reproducción asistida).

STERN, C. (2007). Estereotipos de género, relaciones sexuales y embarazo adolescente en las vidas de jóvenes de diferentes contextos socioculturales en México. Estudios Sociológicos 25(73):105-129. 